\title{
Migration Policies and Migrant Employment Outcomes
}

\author{
Conceptual Analysis and Comparative Evidence for Europe
}

\author{
Alessio Cangiano
}

CMS 2 (4): 417-443

DOI: $10.5117 / \mathrm{CMS} 2014.4 . \mathrm{CANG}$

\begin{abstract}
While a number of studies explored the demographic and human capital attributes affecting migrant socio-economic assimilation, less is known about the role of immigration status on entry. In particular, little evidence exists on the employment outcomes of migrants admitted outside economic immigration channels (family, study, asylum or permit-free) and joining the labour market once in the country of destination. This paper addresses this knowledge gap. Its conceptual framework for understanding how immigration status on arrival influences access to the labour market highlights the role of selectivity mechanisms and of different rights and constraints characterizing the legal situation of migrants who enter via different admission routes. The empirical analysis builds on original estimates of the migrant workforce by immigration status on entry based on the $2008 \mathrm{Ad}$-Hoc Module of the EU Labour Force Survey. Logistic regressions show that immigration status on arrival affects the participation in the labour market, the probability of being unemployed and the access to a job commensurate to the migrant skills. While the participation of family migrants and refugees in the labour market is positively associated with their length of stay, these categories retain a significant unemployment disadvantage in almost all European destinations. This gap becomes particularly evident at the intersection of immigration status and gender. Results suggest the need for a more holistic approach to the governance of labour migration that takes into account the long-term trends of migrant labour supply.
\end{abstract}

Keywords: migration, migrant employment, migration policies, immigration status, Europe 


\section{Introduction}

Migrant workers are generally found to experience significant economic disadvantage relative to the native population. A lower labour participation of migrant women, consistently higher unemployment rates (for both male and female migrants of all educational levels) and a high concentration in underprivileged employment sectors and low-pay jobs (particularly for non-EU nationals) characterise migrant employment in most EU labour markets, although migrant/native gaps significantly vary across EU host countries (e.g. Münz, 2007; Eurostat, 2011). In the current economic climate the immigrant employment gap has also widened as a result of the crisis in most EU destinations - Germany being the notable exception (OECD, 2013: $72)$.

An expanding body of literature investigating the factors responsible for the lower performance of migrants in European labour markets has shown that the socio-demographic background (e.g. age, gender, education, marital status, ethnicity, country of birth) and other measurable attributes (e.g. host language skills, duration of stay) only explain a part of immigrant participation, employment and income differentials ${ }^{1}$ (see for instance Bernardi et al., 2011; Kogan, 2011; Reyneri and Fullin, 2011; Dustmann and Frattini, 2012). Some scholars argued that other factors underpinning migrant poorer outcomes in European labour markets can be identified in the institutional context of the receiving country, including: labour market structures and regulations; the welfare regime; and, most notably, immigration and integration policies - see for example Büchel and Frick (2005), Kogan (2007) and Wanner (2011) $)^{2}$.

A limited direct evidence of the effects of migration policies exists. In particular, quantitative research comparing the labour market outcomes of migrants with different legal status vis-à-vis immigration regulations seems to be rare in the European migration literature. This evidence gap can be ascribed, to a large extent, to the dearth of disaggregated data on the migrant workforce in Europe by legal/immigration status ${ }^{3}$. A lack of interest in policy evaluation by institutional actors has also been indicated as a reason for limited research on the "effectiveness gap" in migration policymaking (Pastore, 2010). The partial exception is some earlier research looking at the employment disadvantage of refugees and/or family migrants and emphasizing the role of labour market restrictions and integration policies that vary by entry category (Bloch, 2007; Bevelander and Pendakur, 2009). 
In order to fill part of the knowledge gap surrounding the experience of different categories of migrants in the EU labour markets, an 'ad hoc' module (AHM) of the EU Labour Force Survey (EU-LFS) on the situation of migrant workers and their descendants was carried out in 2008. This supplementary module included a bespoke set of questions on the reasons for migration, date of acquisition of citizenship, and country of birth of both parents. The combination of these variables offers the unprecedented opportunity to classify the migrant workforce by category of entry. This paper builds on this dataset to shed new light on the diversity of labour market experiences among migrants admitted to EU countries on different grounds (employment, family, humanitarian, ancestry, study etc.). Its overarching aim is to contribute to a better understanding of how migration policies - intended here as the set of laws, rules and practices governing the admission to the country and access to the labour market of nonnational workers - shape migrant patterns of labour market incorporation. Analysis is carried out for the EU-15 as a whole and separately for the six LAB-MIG-GOV target countries (France, Germany, Italy, Spain, Sweden and the UK).

The paper is structured as follows. Next section provides a comparative overview of migration policy trends across EU countries. In section 3, I set out the conceptual links between migration policies and migrant labour market outcomes. This conceptual framework highlights the role of selectivity mechanisms operating in points-based systems and demand-driven labour admissions and of different employment rights and entitlements granted to migrants admitted via different immigration routes. Section 4 describes the methodological approach used for the construction of nine categories approximating immigration status on arrival, its strengths and limitations, and illustrates the composition of the migrant workforce by entry category resulting from this procedure. The core empirical part of the paper uses standard logistic regression analyses to compare the patterns of labour market incorporation by category of entry after controlling for the other demographic and skill attributes typically associated with migrant labour market performance. My results show that immigration status on arrival affects migrant participation in the labour market and their access to jobs commensurate to their skills. In particular, family migrants and refugees retain a significant disadvantage, with these gaps becoming particularly evident at the intersection of immigration status and gender. A final discussion reflects on the main results and highlights some lessons for migration policy-making that can be drawn from the findings. 


\section{Migration policy trends in the EU: an overview}

Migration policy-making in Europe remains largely - and perhaps increasingly - dominated by national policy frameworks. More specifically, while some convergence has been achieved in coordinating measures to prevent irregular migration and in designing a common EU asylum policy, EU countries have been reluctant to give up their national sovereignty in the governance of labour migration. National policy approaches in this field have taken mostly divergent pathways throughout the 199os and until the end of the 2000s (Pastore, 2014).

France, Germany and Sweden consolidated a restrictive and selective approach in the admissions of non-EEA nationals via labour-related channels (tab. 1). In contrast, the UK abandoned the restrictive labour migration approach of post-1973 continental Europe by taking an explicitly open stance towards labour migration in the years of the Blair's administration and admitting significant numbers of skilled workers via a work permit system (the predecessor of the current 5 -tier Points-based system). The greater openness of the UK to labour mobility was then confirmed by the decision not to restrict employment of A8 nationals upon the $2004 \mathrm{EU}$ Enlargement - Sweden also took this stance ${ }^{4}$. A further feature of the UK system - in common with France - has been its popularity as a European destination for international students ${ }^{5}$. Despite formally restrictive labour admission avenues, Italy and Spain progressively developed a de-facto open policy approach to labour migration by regularising the status of large numbers of irregular migrants (Finotelli, 2012; Salis, 2012), most of whom had overstayed temporary visas and had been working in the irregular economy (e.g. Reyneri, 2003).

Significant differences are also apparent in the restrictions (or lack of) used by EU countries to regulate access to the labour market and occupational mobility of non-EU nationals. The wider formal recruitment channels for labour migrants to enter the UK have been paralleled by restrictions in the occupational mobility of work-permit holders (who are typically tied to their employer or to the sector of employment). These restrictions are generally absent or less binding in other EU destinations. In countries where many non-EU migrants were admitted via family (e.g. France), asylum (Sweden) and ancestry-based (Germany) channels, these categories were generally granted unrestricted access to the labour market, potentially playing a substantial role as functional equivalents to labour migration (Pastore, 2014). In contrast, student access to the labour market is time-limited virtually everywhere in Europe. 
Table 1 Salient characteristics of labour migration policies in the 2000s

\begin{tabular}{|c|c|c|c|c|}
\hline Country & $\begin{array}{l}\text { Labour market access of EU-accession } \\
\text { country nationals }^{(a)}\end{array}$ & Employment-related admissions & $\begin{array}{l}\text { Labour market access of non-economic } \\
\text { migrants }\end{array}$ & Integration policies \\
\hline France & $\begin{array}{l}\text { Restricted for A8 migrants; weaker restric- } \\
\text { tions for A2 migrants }\end{array}$ & $\begin{array}{l}\text { Limited number of admissions, weak skill } \\
\text { selectivity (but shortage occupation list in- } \\
\text { troduced in 2007); unrestricted occupa- } \\
\text { tional mobility }\end{array}$ & $\begin{array}{l}\text { Students allowed to work part-time, un- } \\
\text { restricted for other categories }\end{array}$ & $\begin{array}{l}\text { Pre-entry language test for family mi- } \\
\text { grants. Attendance certificate of language } \\
\text { course for unlimited leave to remain. Re- } \\
\text { cognition of qualification allowed but ex- } \\
\text { tremely limited openness to foreign quali- } \\
\text { fications }\end{array}$ \\
\hline Germany & $\begin{array}{l}\text { Restricted for A8 migrants (lifted restric- } \\
\text { tions for highly skilled in 2007); restricted } \\
\text { for A2 migrants }\end{array}$ & $\begin{array}{l}\text { Limited admissions of highly skilled work- } \\
\text { ers; restricted occupational mobility for } \\
\text { work-permit holders }\end{array}$ & $\begin{array}{l}\text { Unrestricted as a general rule (time-limited } \\
\text { restrictions for "tolerated refugees" until } \\
\text { 2008); encouraged ancestry-based admis- } \\
\text { sions (large numbers of ethnic Germans) }\end{array}$ & $\begin{array}{l}\text { Pre-entry language test for family mi- } \\
\text { grants. Compulsory language course for } \\
\text { benefit recipients applying for permanent } \\
\text { residence. Recognition of qualification al- } \\
\text { lowed but extremely difficult (low rate of } \\
\text { recognition), changes in } 2011\end{array}$ \\
\hline Italy & $\begin{array}{l}\text { Admissions tapped through quotas for A8 } \\
\text { migrants between } 2004 \text { and 2006; restric- } \\
\text { tions for A2 immigrants until } 2011\end{array}$ & $\begin{array}{l}\text { Limited legal admissions, no skill selectiv- } \\
\text { ity, preferential quotas for some national- } \\
\text { ities; extensive regularization procedures; } \\
\text { unrestricted occupational mobility }\end{array}$ & $\begin{array}{l}\text { Mostly unrestricted, but access of asylum- } \\
\text { seekers restricted for an initial period of } 6 \\
\text { months; international students only al- } \\
\text { lowed part-time employment; preferential } \\
\text { route for ancestry-based admission quotas } \\
\text { (but low numbers) }\end{array}$ & $\begin{array}{l}\text { Language test for unlimited leave to re- } \\
\text { main. Recognition of qualification allowed } \\
\text { but extremely difficult (low rate of recog- } \\
\text { nition) }\end{array}$ \\
\hline Spain & $\begin{array}{l}\text { Restricted for A8 migrants; restricted access } \\
\text { for A2 migrants between } 2008 \text { and } 2009\end{array}$ & $\begin{array}{l}\text { No explicit skill selectivity; extensive regu- } \\
\text { larization procedures; restricted occupa- } \\
\text { tional and geographical mobility before the } \\
\text { first renewal of stay permits }\end{array}$ & $\begin{array}{l}\text { Time-limited restrictions for international } \\
\text { students (but low numbers); } 6 \text { months } \\
\text { waiting period for asylum seekers; unrest- } \\
\text { ricted for other categories; preferential } \\
\text { route for ancestry-based admission quotas }\end{array}$ & $\begin{array}{l}\text { Voluntary participation in state-funded } \\
\text { language courses for new arrivals. Lan- } \\
\text { guage test for applicants for regularization. } \\
\text { Recognition of qualification allowed but } \\
\text { extremely difficult (low rate of recognition) }\end{array}$ \\
\hline
\end{tabular}




\begin{tabular}{|c|c|c|c|c|}
\hline Country & $\begin{array}{l}\text { Labour market access of EU-accession } \\
\text { country nationals }\end{array}$ & Employment-related admissions & $\begin{array}{l}\text { Labour market access of non-economic } \\
\text { migrants }\end{array}$ & Integration policies \\
\hline Sweden & & $\begin{array}{l}\text { Limited number of admissions, no skill se- } \\
\text { lectivity (but change with } 2008 \text { labour mi- } \\
\text { gration law); restricted occupational mobi- } \\
\text { lity for the first two years }\end{array}$ & $\begin{array}{l}\text { Time-limited restrictions for international } \\
\text { students; unrestricted for other categories; } \\
\text { preferential access for those who have lived } \\
\text { in another Nordic country }\end{array}$ & $\begin{array}{l}\text { Compulsory attendance of language course } \\
\text { for asylum seekers (voluntary for other mi- } \\
\text { grants). Recognition of qualification diffi- } \\
\text { cult, often delegated to the market }\end{array}$ \\
\hline UK & $\begin{array}{l}\text { Unrestricted for A8 migrants; restricted for } \\
\text { A2 migrants (agriculture, hospitality and } \\
\text { self-employment) }\end{array}$ & $\begin{array}{l}\text { Extensive recruitment of highly skilled } \\
\text { workers, restricted occupational mobility for } \\
\text { work-permit holders }\end{array}$ & $\begin{array}{l}\text { Restricted for asylum seekers before recog- } \\
\text { nition of refugee status; international stu- } \\
\text { dents only allowed part-time employment; } \\
\text { unrestricted for family members and an- } \\
\text { cestry-based admissions (low numbers } \\
\text { within Tier 5) }\end{array}$ & $\begin{array}{l}\text { Pre-entry language test for family migrants } \\
\text { and migrants entering via the point-based } \\
\text { system. Language test for unlimited leave } \\
\text { to remain. Recognition of qualification } \\
\text { comparatively easy for nationals of Com- } \\
\text { monwealth countries }\end{array}$ \\
\hline
\end{tabular}

Notes: (a) A8 countries (joined the EU on ${ }^{\text {st }}$ May 2004): (zech Republic, Estonia, Latvia, Lithuania, Hungary, Poland, Slovakia and Slovenia. A2 countries (joined the EU on $1^{\text {st January } 2007): ~ B u l g a r i a ~}$ and Romania

Source: table compiled by Ester Salis based on LAB-MIG-GOV country reports. 
While synthesizing the wide realm of integration policies across EU countries is beyond the scope of this paper, the last column of table 1 points to significant differences - e.g. in the use of pre-entry language tests for some categories of new arrivals and in the provision of post-entry language courses - but also to some similarity, particularly in the limited provision for the recognition of qualifications obtained overseas (the UK is a partial exception as far as Commonwealth migrants are concerned).

\section{Migration policies and immigrant incorporation in the labour market: conceptual underpinning}

The potential impact of migration policies on the economic outcomes of the migrant workforce is multifaceted. First, by establishing the number and/or individual and professional attributes of labour migrants admitted to the country, migration policies influence the size and characteristics of the migrant workforce selecting those workers who are supposedly most in demand in the host economy. The selection of new arrivals on the basis of human capital or skills (e.g. educational titles and knowledge of host country language) is explicit in points-based systems (e.g. in the UK) but some degree of selectivity is also implicit in quota systems and schemes used to recruit lesser skilled workers in specific jobs (e.g. care workers) or economic sectors (e.g. agriculture). Selection mechanisms are also in place when preference in filling job vacancies is accorded on the basis of nationality, such as the preferential treatment of EU workers within the EU labour market, or when bilateral agreements are in place with countries of origin. Although not driven by an economic rationale, the admission of migrants via 'non-economic' immigration channels (mainly dependants, refugees and students) also contributes to shaping the labour force because these categories are generally entitled to work ${ }^{6}$. The recent introduction of preentry conditions such as language tests for family migrants is another selection mechanism that supposedly enhances opportunities for economic and social inclusion (Bonjour, 2014).

The second major way in which migration policies are likely to influence the demographic composition and labour outcomes of the migrant workforce is by regulating (and restricting) access to the labour market of the different categories of non-national workers who are residing in the country. Different types of residence and work permits carry different rights and entitlements establishing the duration of the permit and possibility for renewal, access to the labour market, and the possibility to apply 
for permanent residence or citizenship. While highly skilled labour migration routes (e.g. points-based systems) do not normally carry significant initial restrictions and lead to a relatively smooth transition to full citizenship rights, temporary labour migration schemes typically allow migrants to work only in specific sectors (e.g. agriculture) and restrict settlement opportunities (e.g. Ruhs, 2011) ${ }^{7}$. Similarly, access to the labour market of other immigration categories may be, to some extent, restricted. For example, asylum seekers may not be allowed to work while their asylum applications are pending (Bloch, 2007). International students are normally allowed to work only on a part-time basis (e.g. in the UK and Germany) and granted a limited period after the completion of their studies to find a job offer entitling them to a work permit. In the context of the 2004 and 2007 EU enlargements, the transitional arrangements adopted by most EU15 countries to restrict access to their labour market and welfare benefits of new EU-12 citizens were also an example of normative framework temporarily limiting employment opportunities on the basis of nationality. Policies regulating status changes (e.g. for people willing to shift from labour to dependent visas or vice-versa), status regularization (i.e. allowing previously irregular migrants to take up legal employment) and, at the other end of the migrant legal journey, access to citizenship (in relation to the possibility to take up public sector jobs reserved to EU or hostcountry nationals) may also affect migrant opportunities in the host labour market ${ }^{8}$.

Lastly, employment pathways of different immigrant categories are likely to be influenced by policies aimed at encouraging labour participation and improving migrants' employability. Access of foreign nationals to the whole set of "mainstream" government programmes, benefits and services addressing exclusion from the labour market is often subject to temporary restrictions. However, integration policies aiming to tackle specific factors of migrant socio-economic exclusion - e.g. language courses, vocational training courses, and support in the recognition of qualification obtained abroad - may also be in place. Non-economic migrants (especially dependants and refugees) are the main target groups of these measures $^{9}$.

The above discussed conceptual framework and characteristics of national migration regimes feed into the empirical approach of this paper by suggesting a set of assumptions that can be placed under empirical scrutiny. The overarching hypothesis is that immigration policies are likely to shape not only the categorical composition of immigration flows, but also the labour market outcomes of the different categories of migrants. In the 
short term, an advantage for economic migrants should arise from professional/skill selection mechanisms that fine-tune migrant characteristics to labour demand - as well as from the different nature and motivations of non-economic migration. Nevertheless, the impact of the immigration category may be assumed to decrease with the duration of stay because restrictions to employment and benefits are lifted and/or because of the role of employment support structures targeting immigrant exclusion. Category-specific selection processes are also likely to operate, particularly for immigration categories that are more temporary in nature ${ }^{10}$. Impact of the immigration category on entry is also expected to vary by sex because of the gender-specific nature of some immigration channels (especially family reunification). While some consistency in the differential outcomes of labour and non-economic migrants can be expected in all national contexts, potentially divergent trajectories for some categories as a result of country-specific entry criteria, conditions attached to the different immigration statuses and the different capacity of national integration policies to maximise employment opportunities of newcomers can also be anticipated.

\section{$4 \quad$ Empirical estimates: the migrant workforce by category of entry}

Empirical analyses included in this paper are based on statistical exploitation of the EU-LFS AHM $2008^{11}$. Despite some well-known limitations in quality and coverage $\mathrm{e}^{12}$, the LFS is commonly used across the EU to produce data on migrant workers in employment and includes sample sizes for the migrant workforce large enough to conduct disaggregated analyses in most EU-15 countries (Eurostat, 2010). Given the policy-related nature of the core questions addressed in this paper, I focused my analysis on first generation migrants, namely foreign-born individuals who migrated to the country of destination when they were 15 or older - and were in the age range 15-64 at the time of the survey. The core component of the methodology consisted of the construction of nine categories approximating immigration status on arrival. Due to the lack of specific information on the type of permit/ visa (or lack of) held by migrants when they entered the country, immigration categories were derived by combining information provided by the core LFS module on country of birth, nationality and year of arrival, with 2008 AHM variables on the country of birth of parents, main reason for (last) migration and the year of acquisition of citizenship. Nine immigra- 
tion categories were defined: 1) ancestry-based ${ }^{13}$; 2) EU-15 / EFTA ${ }^{14}$ mi- $^{-}$ grants; 3) Post-enlargement EU-12 migrants ${ }^{15}$; 4) labour migrants with a job found before migrating (including intra-company transfers); 5) labour migrants with no job found before migrating; 6) migrant students; 7) international protection (asylum seekers); 8) family migrants (including both marriage and family reunification); and 9) other migrants (residual category). For non-EEA nationals (categories 4 to 9) immigration categories were attributed building of the assumption that the reported reason for migration (variable MIGREAS) was a proxy for the type of entry visa. For Germany, a bespoke procedure (based on the correspondence between year of entry and year of acquisition of citizenship for migrants coming from Eastern Europe and the former Soviet Union) was used to capture ethnic Germans (Spätaussiedler) ${ }^{16}$.

This approach is affected by apparent limitations. Employment-related categories are defined in generic terms, with no explicit reference to country-specific visa types for the admission of labour migrants. Importantly in countries highly affected by irregular migration such as Italy and Spain ${ }^{17}$, it is not possible to identify those who entered the country without a residence authorization (including both irregular migrants and those overstaying tourist or visitor visas). More in general, the assumption that the stated motivation for migration corresponds to the actual type of permit/visa held by the migrant on arrival is a strong one, with implications for the definition of immigration categories that are hard to gauge. The identification of descendants of emigrants is also imprecise because the dataset only includes information on the country of birth of parents and not of the previous generations. In addition, analysis based on the retrospective observation of the stock of migrants living in the country at the time of the survey is affected by the potentially highly selective nature of return migration (or re-migration). Selection processes are likely to differ by immigrant category because labour and study migration is more temporary in nature than family and asylum migration, as shown by analyses of UK and Swedish official data (Statistics Sweden, 2011; Achato et al., 2013). While all these caveats have to be borne in mind in the interpretation of the results, the broad trends captured by my estimates are consistent with other data sources - such as the OECD estimated composition of the immigrant flows by category of entry (Lemaitre et al., 2007; OECD, various years) and with prior expectations based on policy differences in the national admission systems reviewed in section 2 .

The results of this procedure reveal a very different composition of the migrant workforce by category of entry across the six LAB-MIG-GOV target 
countries $^{18}$. Labour admissions account for only 1 in 10 (or less) of the recent migrant working-age population in countries where immigration policies predominantly focused on rights-based admissions (France, Germany and Sweden). Sweden mostly admitted non-EU migrants on family and humanitarian grounds - with the largest proportion of asylum seekers $(20 \%)$ and family members $(43 \%)$ in the six countries. Germany stands out for the largest share of ancestry-based migrants (17\%), reflecting the still large (although decreasing) number of arrivals of Ethnic Germans from the former Soviet Union in the late 1990s and early 2000s. In the UK, the relatively high openness to skilled labour migration resulted in more nonEEA labour migrants entering the country with a job offer (i.e. via the work permit system) than without, while demand for lesser skilled workers has been met by post-enlargement EU-12 migrants ( 1 in 5 among recent arrivals). The UK, together with France, has also been the most popular destination for international students (14\% of total admissions in both countries, twice as large as the EU-15 average). Given that in Italy and Spain there has long been virtually no provision for obtaining a labour entry visa without a job offer (Salis, 2012; Finotelli, 2012), it can be assumed that most recent migrants who entered these countries with no residence authorisation or overstaying a temporary visa were included in the category 'employment without a job' ( $41 \%$ of the migrant working age population in 2008 in both countries). However, results for the two Southern European destinations seem to understate the presence of post-enlargement EU-12 migrants - in 2008 Romanians were already amongst the largest immigrant groups in both countries. This is probably due to the aforementioned limitations of the LFS in recording recent arrivals.

A diachronic comparison of the composition by immigration category of the recent and long-established migrant workforce (figures 1.a and 1.b) seems to reveal significant changes over the last decade. With some national differences, these include: a decrease in the share of ancestry-based arrivals (particularly in Germany) and of immigration from other EU-15 countries (Spain and Sweden); a decline of humanitarian migrants (Sweden and Germany) ${ }^{19}$; a general increase in the proportion of labourrelated flows (Spain and UK), particularly when the predominantly employment-oriented characterization of EU-12 migration is taken into account; and the growing importance of international student mobility (France, Germany and the UK). 
(a) recent migrants (entry between 1998 and 2007)

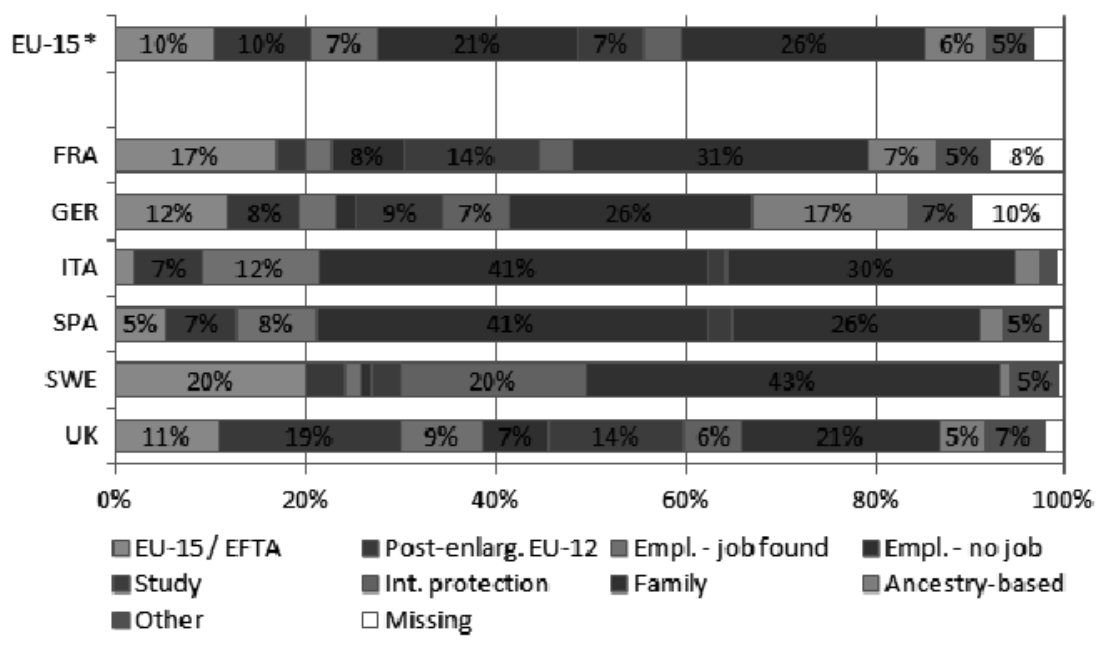

(b) long-estalished migrants (entry before 1998)

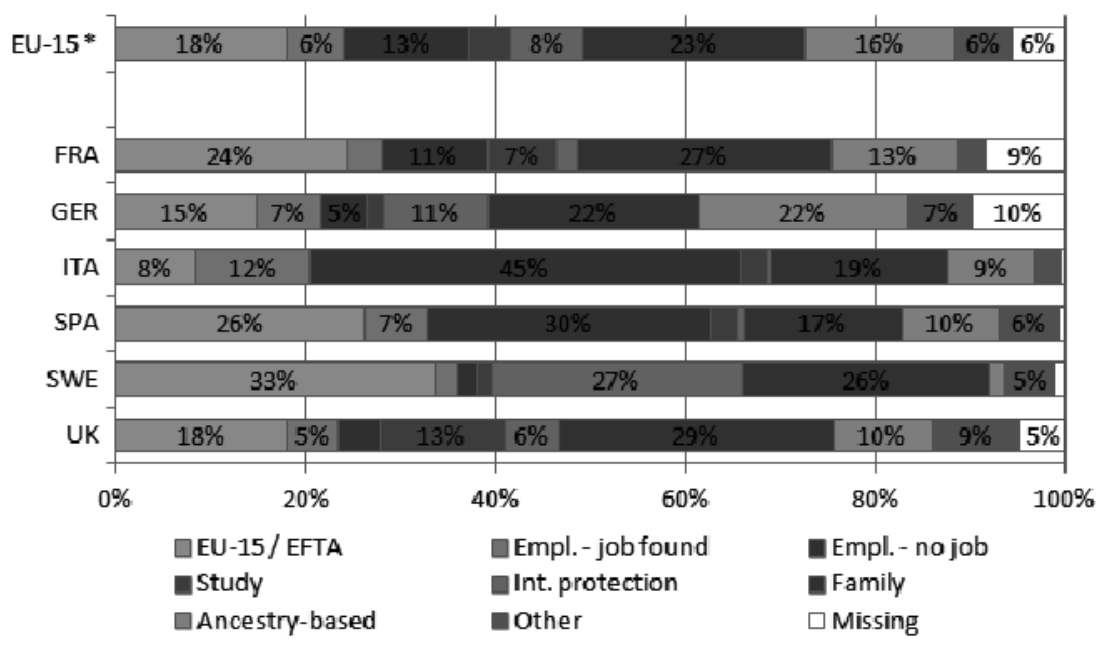

Figure 1 Composition of the migrant workforce by immigration status on entry and country of destination, recent and long-established migrants. EU-15 and selected countries, $2008(\%)$

Own estimates based on the EU-LFS, 2008 Ad-hoc module. 


\section{$5 \quad$ Regression analyses}

Standard binomial logistic regressions were used to 'isolate' the impact of the immigration category on entry after controlling for the demographic and social attributes (age, sex, education, duration of stay, relation to the head of the household, language skills) that are typically identified as the main determinants of migrant labour market outcomes. Estimates of the differences between categories of entrants and the domestic labour force ${ }^{20}$ were produced for: i) the probability of being economically active; ii) the probability of being unemployed (for those who are active); and iii) the probability of being overqualified for the current job (for those who are employed and have medium or high qualifications).

All model specifications were statistically significant in terms of labour market participation, unemployment and over qualification are statistically significant in terms of both variance of the data explained by the model and contribution of the main predictor of interest and other control variables. However, the immigration category contributes to a lower part of the log likelihood accounted for by the model than some other covariates typically associated with labour market outcomes such as education, age and sex. The models describing the determinants of unemployment and over qualification capture a smaller portion of the variability than those on the determinants of labour market participation.

Overall results provide support for the assumption that, ceteris paribus, immigration category on entry plays a role in shaping migrant employment opportunities and outcomes, with statistically significant cross-category variations found for all three labour market indicators - see Table 2. Unsurprisingly the effect of the immigration category on the probabilities of being active and unemployed appears to be stronger upon or soon after arrival (Model 2). Amongst recent arrivals, those who entered with a job offer are by far the most likely to be active in the labour market. They are also the only category less likely than the domestic workforce to be unemployed. Labour migrants without a job on entry and post-Enlargement EU12 migrants have levels of economic activity and unemployment not different from the domestic labour force. In contrast, all other categories are less likely to participate in the labour market than the domestic working age population and have higher probabilities of being unemployed, with students, asylum seekers and family members showing the lowest levels of participation and asylum seekers by far the highest risk of joblessness. The immigrant gap is even higher in terms of probability of being employed in a job matching educational qualifications, with all categories of medium- 
and highly-educated migrants (except EU-15 workers) more likely than the domestic workforce to be overqualified for their current job. Labour migrants entering without a job offer, asylum seekers and post-enlargement EU-12 migrants experience the largest gaps, while comparatively lower levels of over qualification are found for those with a job before migrating.

Table 2 Logistic regressions for the probability of being economically active, unemployed and overqualified. EU-15, alternative model specifications

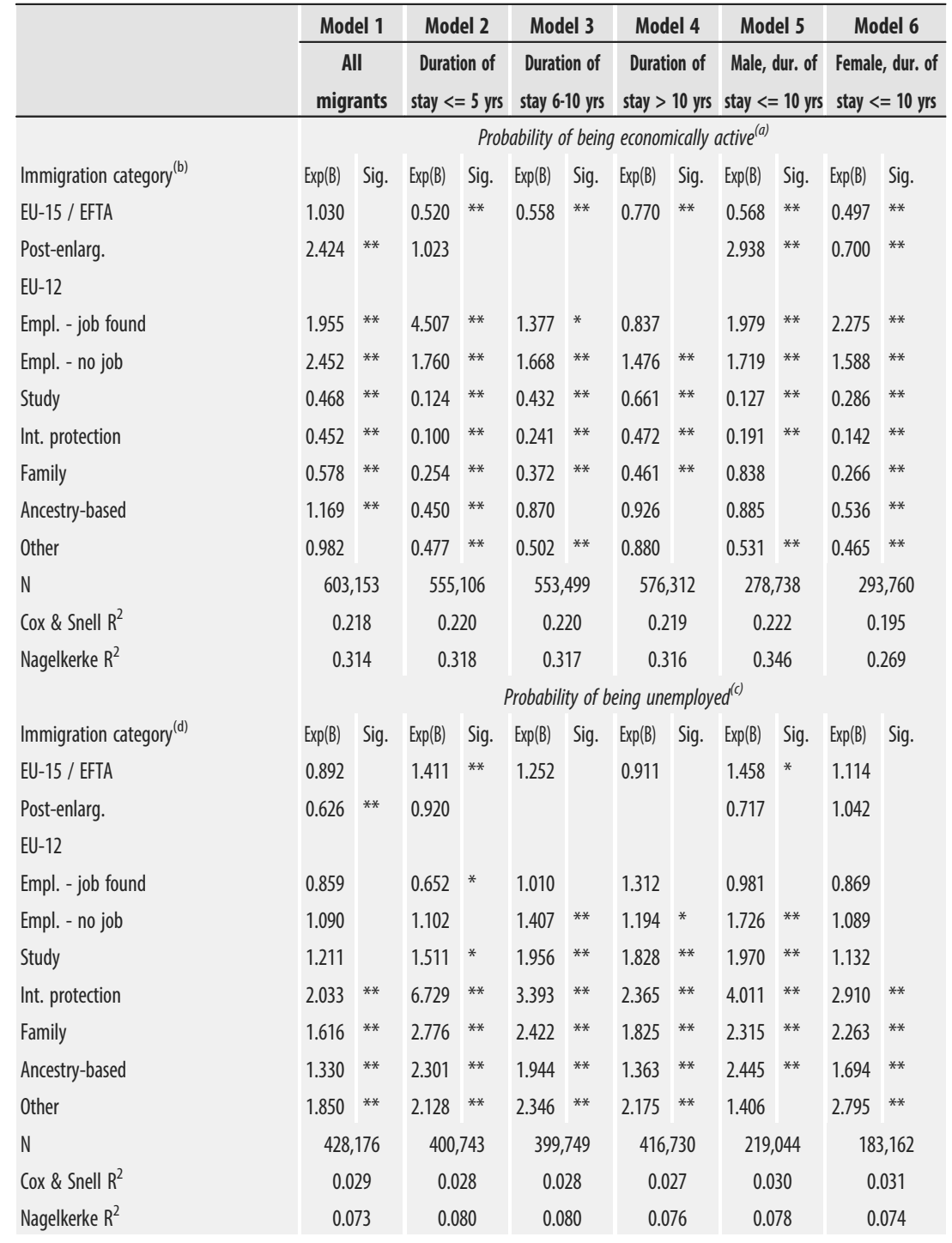




\begin{tabular}{|c|c|c|c|c|c|c|c|c|c|c|c|c|}
\hline & \multicolumn{2}{|c|}{ Model 1} & \multicolumn{2}{|c|}{ Model 2} & \multicolumn{2}{|c|}{ Model 3} & \multicolumn{2}{|c|}{ Model 4} & \multicolumn{2}{|c|}{ Model 5} & \multicolumn{2}{|c|}{ Model 6} \\
\hline & \multicolumn{2}{|c|}{$\begin{array}{c}\text { All } \\
\text { migrants }\end{array}$} & \multicolumn{2}{|c|}{$\begin{array}{l}\text { Duration of } \\
\text { stay }<=5 \text { yrs }\end{array}$} & \multicolumn{2}{|c|}{$\begin{array}{l}\text { Duration of } \\
\text { stay 6-10 yrs }\end{array}$} & \multicolumn{2}{|c|}{$\begin{array}{l}\text { Duration of } \\
\text { stay }>10 \text { yrs }\end{array}$} & \multicolumn{2}{|c|}{$\begin{array}{l}\text { Male, dur. of } \\
\text { stay <= } 10 \text { yrs }\end{array}$} & \multicolumn{2}{|c|}{$\begin{array}{l}\text { Female, dur. of } \\
\text { stay }<=10 \text { yrs }\end{array}$} \\
\hline & \multicolumn{12}{|c|}{ Probability of being overqualified ${ }^{(e)}$} \\
\hline Immigration category ${ }^{(f)}$ & $\operatorname{Exp}(B)$ & Sig. & $\operatorname{Exp}(B)$ & Sig. & $\operatorname{Exp}(B)$ & Sig. & $\operatorname{Exp}(B)$ & Sig. & $\operatorname{Exp}(B)$ & Sig. & $\operatorname{Exp}(B)$ & Sig. \\
\hline EU-15 / EFTA & 0.797 & * & 0.850 & & 0.716 & & 1.083 & & 0.609 & ** & 1.055 & \\
\hline Post-enlarg. EU-12 & 4.573 & ** & 5.641 & ** & & & & & 5.481 & $* *$ & 6.190 & $* *$ \\
\hline Empl. - job found & 1.897 & ** & 1.827 & ** & 3.171 & $* *$ & 2.170 & ** & 1.830 & $* *$ & 3.449 & $* *$ \\
\hline Empl. - no job & 4.614 & ** & 7.421 & ** & 6.113 & ** & 4.657 & ** & 4.040 & ** & $\begin{array}{l}12.0- \\
48\end{array}$ & $* *$ \\
\hline Study & 1.448 & ** & 2.717 & ** & 1.695 & $* *$ & 1.230 & & 2.254 & $* *$ & 1.915 & ** \\
\hline Int. protection & 3.127 & ** & 6.419 & ** & 7.051 & $* *$ & 2.768 & ** & 6.914 & $* *$ & 7.001 & ** \\
\hline Family & 3.273 & $* *$ & 4.846 & $* *$ & 4.799 & $* *$ & 3.053 & ** & 4.495 & $* *$ & 4.983 & $* *$ \\
\hline Ancestry-based & 2.202 & $* *$ & 2.985 & ** & 3.241 & $* *$ & 2.241 & ** & 3.055 & $* *$ & 3.145 & $* *$ \\
\hline Other & 2.059 & $* *$ & 1.813 & ** & 3.735 & $* *$ & 2.103 & ** & 3.106 & $* *$ & 2.538 & ** \\
\hline N & \multicolumn{2}{|c|}{277,134} & \multicolumn{2}{|c|}{256,060} & \multicolumn{2}{|c|}{255,101} & \multicolumn{2}{|c|}{265,776} & \multicolumn{2}{|c|}{136,147} & \multicolumn{2}{|c|}{125,050} \\
\hline Cox \& Snell $R^{2}$ & \multicolumn{2}{|c|}{0.063} & \multicolumn{2}{|c|}{0.054} & \multicolumn{2}{|c|}{0.052} & \multicolumn{2}{|c|}{0.046} & \multicolumn{2}{|c|}{0.057} & \multicolumn{2}{|c|}{0.069} \\
\hline Nagelkerke $R^{2}$ & \multicolumn{2}{|c|}{0.114} & \multicolumn{2}{|c|}{0.100} & \multicolumn{2}{|c|}{0.098} & \multicolumn{2}{|c|}{0.087} & \multicolumn{2}{|c|}{0.108} & \multicolumn{2}{|c|}{0.123} \\
\hline Covariates $^{(g)}$ & \multicolumn{12}{|c|}{ Sex, age, education, relation to head of household, language, duration of stay } \\
\hline
\end{tabular}

Legend: ${ }^{* *}$ statistically significant at $99 \%$ confidence level; ${ }^{*}$ statistically significant at $95 \%$ confidence level. Notes: (a) Dependent variable: working status ( $0=$ inactive, $1=$ active). (b) Reference category: domestic working age population (native-born + foreign-born who migrated when younger than 15). (c) Dependent variable: employment status ( $0=$ employed, $1=$ unemployed). (d) Reference category: domestic labour force (native-born + foreign-born who migrated when younger than 15). (e) Dependent variable: overqualified ( $0=$ no, $1=y e s)$. Overqualification was defined by comparing education (only for those with medium and high educational levels) with the occupational level (Low = ISCO 9, Medium = ISCO 4-8, High = ISCO 1-3). (f) Reference category:

domestic employment (native-born + foreign-born who migrated when younger than 15). (g) Age (15-24, 25-39, 40-54, 55-64); education (Low = ISCED 0-2, Medium = ISCED 3-4, High = ISCED 5-6); relationship to head of the household (head of household, spouse or partner, child or ascendant, other); language (no need to improve language skills to get a job; need to improve language skills to get a job); duration of stay (native-born, 1-4 years, 5-9 years, 10-19 years, 20 years or more).

Source: Own estimates based on the EU-LFS, 2008 Ad-hoc module.

As duration of stay increases (models 3 and 4), partial convergence of employment outcomes to those of the domestic workforce is observed. This implies that after 10 years or more differences across immigration categories are also greatly reduced: on the one hand, labour migrants lose all or part of their advantage in participation and employment levels; on the other, the participation and employment gap significantly declines amongst all non-economic categories, particularly humanitarian migrants. However, even in the long term those who entered via asylum, family reunification and - perhaps surprisingly - study routes retain some gap in their access to employment. The assimilation hypothesis that migrant employment outcomes become more similar to those of the domestic workforce as their duration of stay increases - finds some em- 
pirical support also in terms of access to qualified jobs, but large gaps remain even after 10+ years of residence for most categories, especially labour migrants who entered without a job offer. Students are the main exception, being the only non-EEA migrant group not experiencing higher risk of getting a job below their qualification if they stay for 10 or more years. A singularity is also that there is little or no change in the differentials between native and migrant probabilities of being overqualified over the first 5-10 years.

Analyses disaggregated by sex (Models 5 and 6) show some significant gender differences. In terms of activity levels, a gender gap is mostly visible for two categories: post-enlargement EU-12 male migrants outperform labour participation rates of their domestic counterpart (and of all other categories of male migrants), which is not the case for post-enlargement EU-12 migrant women; similarly, the levels of exclusion from the labour market of migrant spouses are significantly higher only amongst women, while migrant men are not less likely than the domestic working age population to look for a job if they enter the country via the family reunification route. Comparisons by sex of the probability of being unemployed display less marked differences across categories, with migrant men generally facing higher risks of unemployment than women compared to the native labour force for all immigration categories. Perhaps the most striking gender difference is observed in the levels of over qualifications of labour migrants, with female migrant workers (particularly if entering without a job offer) experiencing a much larger gap in accessing qualified jobs matching their educational level than male labour migrants. This result may be ascribable - at least partly - to the vast increase in the employment of migrant women (many of whom educated Eastern Europeans) in low skilled jobs in the household and care sector (Cangiano, 2014). In contrast, similarly high levels of disadvantage amongst men and women are observed for non-economic entry categories.

Some methodological caveats in the interpretation of these findings should be considered in relation to possible selection effects operating differently for the various immigration categories. The immigrant gap in the probability of being active might vary by category because of genuine differences in the propensity to participate in the labour market and not only because of access conditions dictated by the immigration status. This does not apply to the probabilities of being unemployed and overqualified, because only people who are, respectively, willing to work or currently employed are considered in the analysis. Employment levels might how- 
ever be affected by the type of jobs that different categories of migrants do, e.g. migrants who enter the country with a job offer are likely to be overrepresented in highly skilled jobs that tend to be more secure and less exposed to the risk of unemployment. Category-selective impact of return migration (e.g. temporary migrant workers and students more likely to leave than family migrants) and the changing composition by country of origin of immigrant flows over time (e.g. the rise in East-Asian student migration) can also affect the comparison of labour market outcomes by duration of stay (Models 2, 3 and 4).

The general definition of entry categories used in this paper does not allow for separate analysis of the short-term effects of country-specific admission criteria and restrictions attached to non-EEA immigration statuses before migrants are granted permanent residency. However, national-level analyses can provide some clues on the differential capacity of European migration regimes to enhance labour market inclusion of different categories of migrants in the long term. To this end, regression models shown in table 3 only included migrants who spent at least five years in the host country ${ }^{21}$.

Table 3 Country-level logistic regressions for the probability of being economically active, unemployed and overqualified (duration of stay $>5 \mathrm{yrs}$ )

\begin{tabular}{|c|c|c|c|c|c|c|c|c|c|c|c|c|}
\hline \multirow[b]{3}{*}{ Immigration category ${ }^{(b)}$} & \multicolumn{2}{|c|}{ France } & \multicolumn{2}{|c|}{ Germany } & \multicolumn{2}{|c|}{ Italy } & \multicolumn{2}{|c|}{ Spain } & \multicolumn{2}{|c|}{ Sweden } & \multicolumn{2}{|c|}{ UK } \\
\hline & \multicolumn{12}{|c|}{ Probability of being economically active $e^{(a)}$} \\
\hline & $\operatorname{Exp}(B)$ & Sig. & $\operatorname{Exp}(B)$ & Sig. & $\operatorname{Exp}(B)$ & Sig. & $\operatorname{Exp}(B)$ & Sig. & $\operatorname{Exp}(B)$ & Sig. & $\operatorname{Exp}(B)$ & Sig. \\
\hline EEA & 1.126 & & 0.816 & * & 0.577 & * & 0.519 & ** & 0.286 & ** & 0.720 & * \\
\hline Empl. - job found & 1.210 & & 0.830 & & 1.848 & ** & 1.391 & & & & 2.090 & * \\
\hline Empl. - no job & & & & & 2.639 & ** & 2.029 & ** & & & 0.745 & \\
\hline Study & 0.516 & ** & & & & & & & & & 0.488 & $* *$ \\
\hline Int. protection & & & 0.410 & ** & & & & & 0.300 & ** & 0.172 & $* *$ \\
\hline Family & 0.432 & ** & 0.391 & ** & 0.709 & ** & 0.875 & & 0.289 & $* *$ & 0.184 & $* *$ \\
\hline Ancestry-based & 0.572 & ** & 1.223 & * & 0.639 & * & 1.272 & & & & 0.420 & ** \\
\hline Other & 0.910 & & 0.672 & $* *$ & 0.853 & & 1.225 & & 0.237 & $* *$ & 0.405 & $* *$ \\
\hline N & 37,9 & & 26 & & 105, & & 66,3 & & 45 & 373 & & 2,027 \\
\hline Cox \& Snell $R^{2}$ & 0.2 & & 0.1 & & 0.28 & & 0.2 & & 0.1 & 99 & & .167 \\
\hline Nagelkerke $R^{2}$ & 0.4 & & 0.2 & & 0.3 & & 0.3 & & 0.3 & 14 & & .248 \\
\hline
\end{tabular}




\begin{tabular}{|c|c|c|c|c|c|c|c|c|c|c|c|c|}
\hline \multirow[b]{3}{*}{ Immigration category ${ }^{(\mathrm{d})}$} & \multicolumn{2}{|c|}{ France } & \multicolumn{2}{|c|}{ Germany } & \multicolumn{2}{|c|}{ Italy } & \multicolumn{2}{|c|}{ Spain } & \multicolumn{2}{|c|}{ Sweden } & \multicolumn{2}{|c|}{ UK } \\
\hline & \multicolumn{12}{|c|}{ Probability of being unemployed ${ }^{(c)}$} \\
\hline & $\operatorname{Exp}(B)$ & Sig. & $\operatorname{Exp}(B)$ & Sig. & $\operatorname{Exp}(B)$ & Sig. & $\operatorname{Exp}(B)$ & Sig. & $\operatorname{Exp}(B)$ & Sig. & $\operatorname{Exp}(B)$ & Sig. \\
\hline EEA & 1.061 & & 0.577 & ** & 0.281 & & 1.534 & & 1.460 & & 1.086 & \\
\hline Empl. - job found & 1.931 & ** & 1.549 & ** & 0.530 & & 1.232 & & & & 1.449 & \\
\hline Empl. - no job & & & & & 1.026 & & 1.564 & $* *$ & & & 1.352 & \\
\hline Study & 1.910 & * & & & & & & & & & 1.186 & \\
\hline Int. protection & & & 1.776 & ** & & & & & 3.427 & ** & 2.264 & $* *$ \\
\hline Family & 2.888 & $* *$ & 1.046 & & 1.857 & ** & 1.909 & ** & 2.846 & ** & 2.327 & ** \\
\hline Ancestry-based & 2.248 & ** & 0.927 & & 2.153 & * & 2.364 & ** & & & 1.319 & \\
\hline Other & 1.470 & & 1.887 & ** & 1.095 & & 2.342 & ** & 3.138 & * & 1.242 & \\
\hline N & 26, & 122 & 20, & & 64,1 & & 45 & 984 & 39, & 051 & & 5,954 \\
\hline Cox \& Snell $R^{2}$ & 0.0 & 36 & 0.0 & & 0.0 & & 0.0 & & 0.0 & 61 & & .039 \\
\hline \multirow[t]{2}{*}{ Nagelkerke $\mathrm{R}^{2}$} & 0.0 & & 0.0 & & 0.1 & & 0.0 & & 0.1 & 69 & & .116 \\
\hline & \multicolumn{12}{|c|}{ Probability of being overqualified ${ }^{(e)}$} \\
\hline Immigration category $^{(f)}$ & $\operatorname{Exp}(B)$ & Sig. & $\operatorname{Exp}(B)$ & Sig. & $\operatorname{Exp}(B)$ & Sig. & $\operatorname{Exp}(B)$ & Sig. & $\operatorname{Exp}(B)$ & Sig. & $\operatorname{Exp}(B)$ & Sig. \\
\hline EEA & 0.996 & & $\begin{array}{l}0.8834- \\
402283- \\
826486\end{array}$ & & 0.576 & & 1.041 & & 1.189 & & 0.913 & \\
\hline Empl. - job found & 2.834 & ** & 2.805 & ** & 12.194 & ** & 4.492 & ** & & & 0.423 & $* *$ \\
\hline Empl. - no job & & & & & 11.128 & $* *$ & 6.080 & $* *$ & & & 1.488 & \\
\hline Study & 2.516 & $* *$ & & & & & & & & & 1.297 & \\
\hline Int. protection & & & 3.297 & $* *$ & & & & & 3.848 & ** & 2.232 & $* *$ \\
\hline Family & 2.711 & ** & 3.340 & $* *$ & 6.374 & $* *$ & 5.538 & $* *$ & 3.602 & ** & 2.358 & $* *$ \\
\hline Ancestry-based & 1.418 & & 3.717 & ** & 0.859 & & 1.815 & & & & 0.614 & \\
\hline Other & 4.855 & $* *$ & 1.566 & ** & 2.714 & $* *$ & 2.435 & ** & 1.910 & & 1.763 & $* *$ \\
\hline N & 17,8 & 841 & 16, & & 36,3 & & 23 & & 30, & 668 & & 3,849 \\
\hline Cox \& Snell $R^{2}$ & 0.0 & 49 & 0.0 & & 0.0 & & 0.1 & 12 & 0.0 & 35 & & .038 \\
\hline Nagelkerke $\mathrm{R}^{2}$ & 0.0 & 89 & 0.0 & & 0.1 & & 0.1 & 68 & 0.0 & 80 & & .065 \\
\hline Covariates $^{(g)}$ & & & Sex, ag & e, ed & ation, re & elation & to head & of $h$ & sehold, & langua & & \\
\hline
\end{tabular}

Legend: ${ }^{* *}$ statistically significant at $99 \%$ confidence level; ${ }^{*}$ statistically significant at $95 \%$ confidence level. Categories with small numerosity in national samples are not shown.

Notes: (a) Dependent variable: working status ( 0 =inactive, $1=$ active). (b) Reference category: domestic working age population (native-born + foreign-born who migrated when younger than 15). (c) Dependent variable: employment status $(0=$ employed, $1=$ unemployed). (d) Reference category: domestic labour force (native-born + foreign-born who migrated when younger than 15). (e) Dependent variable: overqualified ( $0=$ no, $1=$ yes). Overqualification was defined by comparing education (only for those with medium and high educational levels) with the occupational level (Low = ISCO 9, Medium = ISCO 4-8, High = ISCO 1-3). (f) Reference category:

domestic employment (native-born + foreign-born who migrated when younger than 15). (g) Age (15-24, 25-39, 40-54, 55-64); education (Low = ISCED 0-2, Medium = ISCED 3-4, High = ISCED 5-6); relationship to head of the household (head of household, spouse or partner, child or ascendant, other); language (no need to improve language skills to get a job; need to improve language skills to get a job).

Source: Own estimates based on the EU-LFS, 2008 Ad-hoc module. 
Differences across national contexts seem to reflect - or at least relate to the aforementioned characteristics of national migration regimes. In countries with a de-facto open approach to labour migration (i.e. the UK, Italy and Spain) established labour migrants have generally higher levels of participation in the labour market than the domestic workforce and no or small differences in the levels of unemployment. In contrast, amongst the countries that have been more restrictive in admitting migrant workers, after five or more years of stay labour migrants experience either a large participation gap (Sweden) or a significant employment gap (Germany and France). As regards non-economic migrants, outcomes substantially vary by country of destination. In Italy and Spain family migrants display small participation gaps with the domestic workforce, while this is not the case in the UK and Sweden where settled family migrants - as well as refugees are considerably less likely to be active and more likely to be unemployed. Estimates for Germany suggest that the probability to be in employment for ancestry-based migrants is not significantly different from the domestic labour force.

At national level, the skill underutilization of labour migrants is particularly high in Italy and Spain. In these two countries where migrant recruitment predominantly occurred at the bottom of the skill ladder, labour migrants have either same (Spain) or lower (Italy) probability to be in a job with skill levels congruent to their educational qualifications than non-economic categories. In contrast, the UK is the only country where migrant workers who enter with a job offer are less likely to be overqualified after 5 or more years in the country - and even those entering without a job offer are not significantly different from the domestic workforce. This seems to suggest that the demand-driven work permit system has been relatively effective in meeting the needs for high skilled labour of the UK economy and in providing migrants with relatively good prospects to capitalize on their skills. For all immigration systems prioritising admissions on non-economic grounds, high levels of over qualification are observed: in these countries spouses, asylum seekers (in Sweden and Germany) and ancestry-based migrants (in Germany) who joined the labour market have mostly been employed in jobs below their educational qualifications. This seems to provide some support for the argument of a functional role of non-economic admissions in meeting labour demand at the bottom of the skill ladder and in mitigating demand for lesser skilled work-related admissions from outside the EU (Pastore, 2014). It is also interesting to note the difference between the two countries which have recently admitted the largest numbers of international students (the UK 
and France), as migrants who entered the UK for study reason and stayed on after the completion of their studies had greater chances to find a job matching their qualifications and to 'assimilate' to the domestic workforce.

\section{Conclusions}

Despite some methodological caveats, analyses carried out in this paper provide some robust findings that fill, at least in part, significant evidence gaps in migration research and policy literature. Migrants entering via labour migration channels have systematically higher employment rates than the domestic workforce, while humanitarian and family migrants are, even after controlling for other socio-demographic attributes, the least likely to be employed in all selected countries. The disadvantage of socalled non-economic categories becomes particularly evident at the intersection of immigration status and gender (i.e. for female spouses and asylum seekers). While it is difficult to disentangle the economic, institutional and motivational factors underpinning these employment gaps, evidence that immigration category on entry is associated with differential employment outcomes appears to be robust. Across national admission systems, this results in a negative correlation between openness to labour migration and the gap between domestic and migrant employment rates - i.e. the immigrant employment gap is lower in the UK, Spain and Italy than in Sweden, France and Germany where the proportion of non-economic immigration categories in the migrant workforce is higher.

This is not to say, however, that 'non-economic' migrants are not involved in the labour market once they settle in the country of destination. On the contrary, the majority of them look for and find a job. Indeed an interesting finding of this paper is that the gap between labour and other immigration categories is significantly reduced (or even disappear) for the long-established migrant workforce as a result of higher participation levels of 'non-economic' migrants as well as of lower participation levels of non-EEA labour migrants. While it was not possible to ascertain the role of differential return and re-migration patterns by category of entry, there seems to be strong enough evidence that employment opportunities of family and humanitarian migrants are also likely to improve as they acquire language skills and other competences that are valued in the destination country's labour market.

In terms of 'quality' of migrant employment, evidence presented in this paper reiterates results showing a significant waste of immigrant skills in 
most European economies (e.g. Eurostat, 2011: 51). While all categories of migrants are more likely than the domestic workforce to be overqualified for their job, differences exist in the extent of this outcome. The loss of 'skill potential' relative to the domestic labour force is particularly high for refugees, post-enlargement EU-12 and non-economic immigration categories. This seems to suggest that in countries with limited provision for lesser-skilled labour migration, the employment of family members, refugees and ancestry-based migrants (in Germany) below their qualifications has been functional to meeting the needs for low skilled labour in the economy. However, in several EU countries the loss of skill potential is also significant amongst labour migrants. This is particularly the case in Italy and Spain, where recurrent regularizations of migrants working in lesser skilled occupations implied that medium or highly skilled labour migrants experience even higher chances to be overqualified for their job than non-economic categories. Even more strikingly, female labour migrants (particularly those without a job offer) seem to experience far greater levels of over qualification than their male counterpart. This gender gap is, again, particularly large in Italy and Spain - where non-EU female workers are often employed as domestic helpers and care workers - but also significant in Germany and France.

These findings suggest some key lessons for migration policy-making. The first is that EU labour migration debates are often too narrowly framed - if not misplaced - in portraying a divide between 'economic migrants' that help meet labour shortages and rights-based immigration categories that are referred to as a burden on the welfare system. Our results suggest that a more holistic approach to the governance of labour migration should not only take into account the short-term needs of the labour market (and select those workers who are supposedly most suited to fulfil these needs), but also the long-term trends of migrant labour supply which are characterised by increased economic participation of migrants who entered outside labour migration channels.

The second, related, aspect is that there is still considerable scope for policy interventions enhancing the economic integration of so-called 'noneconomic migrants'. Especially in the short run, the labour market disadvantage of these categories is large, not only in terms of high levels of inactivity - which might be partly voluntary and reflect different motivational factors and migratory plans of these categories - but also in terms of higher unemployment rates. This is particularly the case in countries such as Sweden and France where admissions on family and humanitarian grounds make up a large share of immigrant flows and where much em- 
phasis is placed on migrant integration as a desired outcome of migration policies. Measures to address the initial labour market exclusion and allow migrants who want to work to take full advantage of their potential from (or soon after) arrival should focus on both the removal of institutional barriers (restrictions in the access to employment support services and non-recognition of educational titles) and on enhancing employability (e.g. language and training courses).

Finally, the association between the channels of entry and the levels of over qualification calls for a deeper reflection on - and further analysis of the links between immigrant selection criteria and the matching of migrant skills to labour demand in the host economy. The limited provision for recognition of foreign qualifications and low recognition rates in most EU countries (see tab. 1) clearly testifies to a lack of prioritisation of this issue in migration policies. The current emphasis on formal qualifications as selection criteria that maximise migrant prospects of socio-economic integration may also prove inadequate if skill-selected migrants admitted via Points-Based Systems end up working in low skilled jobs (e.g. Altorjai 2013; Reitz 2013). Innovative solutions are also needed to address the gender dimension of over qualification, for example targeting the needs of women who migrate to follow their partners and experience a disruption in their career path. Yet over qualification has diverse root causes and its non-transient nature implies that further action such as labour market reforms are also needed to enhance migrant prospects of upward socio-economic mobility over the long run. A longitudinal extension of this study could provide further insights into the relationship between selective migration policies and the labour market trajectories of skilled migrants.

\section{Acknowledgements}

This article was developed as part of the international project 'LAB-MIGGOV: Which labour migration governance for a more dynamic and inclusive Europe?', coordinated by FIERI and benefiting from the support of the "Europe and Global Challenges" Programme promoted by Compagnia di San Paolo, Riksbankens Jubileumsfond and VolkswagenStiftung (www.labmiggov.eu). Analysis is based on data from Eurostat, EU Labour Force Survey, 2008 Ad-Hoc Module. The responsibility for all conclusions drawn from the data lies entirely with the author. 


\section{Notes}

1. Less measurable factors may also underpin these gaps, for example discriminatory practices excluding migrants from the most qualifying jobs; and the migrant 'temporary mindset' which makes them more likely to accept low-skilled or low-paid jobs unappealing to local workers because of the comparative gains relative to the conditions prevailing in the migrant country of origin (e.g. Anderson and Ruhs, 2010).

2. For example, some comparative work (Kogan, 2007; Wanner, 2011) analysed the determinants of immigrant economic integration with a multi-level framework including dummy variables and other aggregate indicators representing the migration policy context in different countries, obtaining varying results on the influence of these variables.

3. European censuses and major national household surveys do not record immigration status on entry or the type of permit migrants hold at the time of the data collection. Similarly, administrative data sources (e.g. population registers, social security records) do not normally keep track of the legal situation of migrants as they progress through the system - and also provide limited information on employment. However, register data from Sweden and other Scandinavian countries do include information on the category of entry (Bevelander and Pendakur, 2009).

4. In 2004, transitional restrictions of the right to work for citizens of the eight Central and Eastern European accession countries (Czech Republic, Estonia, Hungary, Latvia, Lithuania, Poland, Slovak Republic, and Slovenia) were adopted by all EU-15 member states except Ireland, Sweden and the UK. Cypriot and Maltese nationals were not subjected to any transitional arrangements. In 2007, initial unrestricted access to the labour market for Bulgarian and Romanian nationals was only granted by Finland and Sweden.

5. Between 2004 and 2010 the UK (16\%), Austria (15\%) and France (12\%) were the EU countries featuring the largest share of international students in tertiary enrolment (OECD, 2013: 34). However, in the UK recent policy restrictions in the student admission and post-study route have produced a marked decrease in immigration for study reason (ONS, 2014: fig. 3.11).

6. However, the question of whether immigration policies actually succeed in letting in only migrants with desired skills and attributes (and whose migratory plans match allocated visas) deserves some critical consideration. Research has shown that some migrants apply for certain types of visa depending on the expectation they have of entering the country (Anderson, 2010). For example, if potential migrants perceive that their prospects of being granted a work permit have decreased as a result of more restrictive criteria, they may decide to apply for a self-employment or a student visa to access the destination country's labour market. In Anderson's words (2010: 308), «immigration controls are not a neutral framework facilitating the sorting of individuals by intentions and identities into particular categories, rather they produce status». At the macro-level, these strategies to circumvent the system might lead to increasing irregular migration or to categorical substitution effects - i.e. the shift of immigration flows from one legal avenue to another (e.g. from labour to family migration) (Czaika and de Haas, 2013).

7. Renewal of work permits is typically conditional on the availability of a job, with jobsearch periods of variable duration after the end of the previous employment relationship. 
8. For example, studies looking at the role of regularization and naturalization in enhancing migrant employment opportunities confirmed the positive impact of these status changes (e.g. Carfagna et al., 2008; OECD, 2010).

9. For example, in Sweden Bevelander and Pendakur (2009) find significant differences in employment trajectories of government assisted refugees, landed refugees and family reunion immigrants and conclude that these differences result from category-specific integration policies.

10. This affects particularly international students: while most of them leave after completing their studies, those who stay are likely to be 'positively' selected because of the requirement to find a job in order to shift to a work permit.

11. A more comprehensive account of the approach used in the construction of the nine immigration categories can be found in Cangiano (2012).

12. Estimates of the migrant population and workforce provided by the LFS are likely to be conservative, although their level of inaccuracy is hard to predict. In particular, irregular migrants are likely to escape the survey. For a detailed account of the limitations of the LFS in producing migration data see Martí and Ródenas (2007).

13. This category includes individuals born abroad but citizens of the country of destination from birth; and migrants whose father and/or mother were born in the country of destination.

14. Nationals of the countries of the European Free trade Association (Iceland, Liechtenstein, Norway and Switzerland) enjoy unrestricted labour mobility in the European Union.

15. For the sake of simplicity, different transitional arrangements for the mobility of new citizens adopted by former member states were not considered. Also, it was not possible to differentiate between EU-10 and EU2 accessions as post 2007 migrants are not sufficiently captured in the dataset.

16. The variable 'Age of acquisition of citizenship' included in the AHM 2008 is in 5 -year age groups, so it was not possible to identify the exact year of acquisition of citizenship. It is also possible that ethnic Germans were somewhat underestimated because my procedure does not capture those whose parents were already German nationals- see Cangiano (2012) for further details.

17. Regularization data for Italy and Spain suggest that in these countries very significant proportions of regular migrants acquired a residence permit (mostly for employment purposes) when they were already living and working irregularly (e.g. Cangiano and Strozza, 2008).

18. It is worthwhile noting that some immigration categories are clearly gender-unbalanced: at EU level, $60 \%$ of recent labour migrants and asylum seekers are men; while $70 \%$ (or more in some destination countries) of family migrants are women (see Cangiano 2012).

19. This is the combined effect of declining asylum applications (Germany) and the drop in recognition rates until the mid-200os (Toshkov and De Haan, 2013).

20. The term 'domestic' working age population is used from here on to include the nativeborn population and foreign-born individuals who migrated when younger than 15 .

21. Comparison across countries is however hindered by different labour market structures. For example, it is no coincidence that immigrant gaps in activity and unemployment are larger in countries where native workers have higher activity rates and lower unemployment levels. This is also true for the probability of being overqualified - the gap is larger in countries with occupational structures skewed towards lower skilled jobs. 


\section{References}

Achato L., Eaton M. \& Jones C. (2013). The migrant Journey - Third Report. Research Report 69, London: Home Office.https://www.gov.uk/government/uploads/system/uploads/attachment_data/file/143930/horr69-report.pdf

Altorjai S. (2013). "Over-qualification of immigrants in the UK". ISER Working Paper Series No. 2013-11, University of Essex: Institute for Social and Economic Research. https://www.iser.essex.ac.uk/publications/working-papers/iser/2013-11.pdf

Anderson B. (2010). "Migration, immigration controls and the fashioning of precarious workers". Work, Employment and Society, 24(2): 300-317.

Anderson B. \& Ruhs M. (2010). "Migrant Workers: Who Needs Them? A Framework for the Analysis of Staff Shortages, Immigration and Public Policy", in: Ruhs M. and Anderson B. (eds.) Who Needs Migrant Workers? Labour Shortages, Immigration and Public Policy, pp. 1552. Oxford: Oxford University Press.

Bernardi F., Garrido L. \& Miyar M. (2011). "The Recent Fast Upsurge of Immigrants in Spain and Their Employment Patterns and Occupational Attainment". International Migration, 49(1): 148-187.

Bevelander P. \& Pendakur R. (2009). "The employment attachment of resettled refugees, refugees and family reunion migrants in Sweden", in Bevelander, P. Hagstrom, M. and Ronnqvist, S. Resettled and Included? The employment integration of resettled refugees in Sweden, pp. 227245. Malmo: Malmo University.

Bloch A. (2007). "Refugees in the UK Labour Market: The Conflict between Economic Integration and Policy-led Labour Market Restriction”. Journal of Social Policy, 37(1): 21-36.

Bonjour S. (2014). "The Transfer of Pre-departure Integration Requirements for Family Migrants among Member States of the European Union". Comparative Migration Studies, 2(2): 203-226.

Büchel F. \& Frick J.R. (2005). "Immigrants' economic performance across Europe - does immigration policy matter? "Population Research and Policy Review, 24(2): 175-212.

Cangiano A. (2012). "Immigration policy and migrant labour market outcomes in the European Union: New evidence from the EU Labour Force Survey". Lab-Mig-Gov working paper, Turin: FIERI.http://www.labmiggov.eu/wp-content/uploads/2012/05/Cangiano-Lab-Mig-Gov-FinalReport-WP4.pdf

Cangiano A. (2014). "Elder Care and Migrant Labor in Europe: A Demographic Outlook.” Population and Development Review, 40(1): 131-154.

Cangiano A. \& Strozza S. (2008). "Foreign Immigration in Southern European Receiving Countries: New Evidences from National Data Sources". In: Bonifazi C., Okólski M., Schoorl, J. and Simon P. (eds.), International Migration in Europe: New Trends, New Methods of Analysis, IMISCOE Research, Amsterdam: University Press, 153-178.

Carfagna S., Gabrielli D., Sorvillo, M.P. \& Strozza S. (2008). "Changes of status of immigrants in Italy: results of a record-linkage on administrative sources”. Paper presented at the European Population Conference, Barcelona. http://epc20o8.princeton.edu/papers/80562

Czaika M. \& De Haas, H. (2013). "The Effectiveness of Immigration Policies". Population and Development Review, 39(3):487-508.

Dustmann C. \& Frattini T. (2012). "Immigration: The European Experience". Norface Migration Discussion Paper No. 2012-01. http://www.norface-migration.org/publ_uploads/NDP_01_12.pdf

Eurostat (2010). Report on the quality of the LFS ad hoc module 2008 on the labour market situation of migrants and their descendants. Doc. Eurostat/F2/EMPL/22/10. Luxemburg: Publications Office of the European Union. http://epp.eurostat.ec.europa.eu/portal/page/portal/employment_unemployment_lfs/documents/Evaluation\%2oreport\%20AHM\%202008.pdf 
Eurostat (2011). Migrants in Europe. A statistical portrait of the first and second generation. Eurostat Statistical Books. Luxemburg: Publications Office of the European Union. http://epp.eurostat.ec.europa.eu/cache/ITY_OFFPUB/KS-31-10-539/EN/KS-31-10-539-EN.PDF

Finotelli C. (2012). "Labour migration governance in contemporary Europe - The case of Spain". Country Report for the LAB-MIG-GOV Project "Which labour migration governance for a more dynamic and inclusive Europe?", FIERI Working Paper. http://www.labmiggov.eu/wpcontent/uploads/2012/04/LABMIGOV_WP1_SPAIN_Final-report.pdf

Kogan I. (2007). Working through barriers: host country institutions and immigrant labour market performance in Europe. Dordrecht: Springer.

Kogan I. (2011). "New Immigrants, Old Disadvantage Patterns? Labour Market Integration of Recent Immigrants into Germany". International Migration, 49(1): 91-117.

Lemaitre G., Liebig T., Thoreau C. \& Fron P. (2007). Standardised statistics on immigrant inflows: results, sources and methods. Paris: OECD.http://www.oecd.org/els/mig/38832099.pdf

Martí M. \& Ródenas C. (2007). "Migration Estimation Based on the Labour Force Survey: An EU15 Perspective". International Migration Review, 41(1): 101-126.

Münz R. (2007). "Migration, Labor Markets, and Integration of Migrants: An Overview for Europe", Policy Paper 3-6, Hamburg: HWWI.http://www.hwwi.org/uploads/tx_wilpubdb/ HWWI_Policy_Paper_3-6_o1.pdf

OECD (various years). International Migration Outlook, Sopemi Report, Paris: OECD.

Office for National Statistics. 2014. "Migration Statistics Quarterly Report, August 2014." Statistical Bulletin. London: ONS. http://www.ons.gov.uk/ons/dcp171778_375307.pdf

Pastore F. (2010). "Managing Migration through the Crisis: Evolving Patterns in European Policies on Labour Migration and Mobility". FIERI Working Paper, http://www.labmiggov.eu/wpcontent/uploads/2012/04/MIGRATION-IN-UNCERTAIN-TIMES-_Working-Paper-FIERI-Dec2010_.pdf

Pastore F. (2014). The Governance of Migrant Labour Supply in Europe, Before and During the Crisis. (Introduction) Comparative Migration Studies, 2(4): 385-415.

Reitz J. (2013). "Closing the Gaps between Skilled Immigration and Canadian Labour Markets: Emerging Policy Issues and Priorities". In Triadafilopoulos (ed.) Wanted and Welcome? Policies for Highly Skilled Immigrants in Comparative Perspective, pp. 147-163, New York: Springer.

Reyneri E. (2003). "Immigration and the underground economy in new receiving South European countries: Manifold negative effects, manifold deep-rooted causes". International Review of Sociology, 13(1): 117-143.

Reyneri E. \& Fullin G. (2011). "Labour Market Penalties of New Immigrants in New and Old Receiving West European Countries”. International Migration, 49(1): 31-57.

Ruhs M. (2011). "Openness, Skills and Rights: An empirical analysis of labour immigration programmes in 46 high- and middle- income countries". Working Paper No. 88, Oxford: Centre on Migration, Policy and Society.

Salis E. (2012). "Labour migration governance in contemporary Europe - The case of Italy". Country Report for the LAB-MIG-GOV Project "Which labour migration governance for a more dynamic and inclusive Europe?" FIERI Working Paper. http://www.labmiggov.eu/wpcontent/uploads/2012/04/LABMIGOV_WP1_Italy_Final-report.pdf

Statistics Sweden (2011). Return migration by time spent in Sweden. Stockholm: SCB.

Toshkov D. \& De Haan L. (2013). "The Europeanization of Asylum Policy: An assessment of the EU impact on asylum applications and recognitions rates". Journal of European Public Policy, 20 (5): 661-683.

Wanner R. (2011). "Immigration Policy and the Economic Integration of Immigrants: A CrossNational Comparison". Prairie Metropolis Centre, Working Paper Series, WP11-01. http:// pcerii.metropolis.net/WorkingPapers/WP1101.pdf 


\section{About the Author}

Alessio Cangiano is Senior Lecturer and Coordinator of the Population and Demography Program at The University of the South Pacific, member of the LAB-MIG-GOV research team and Research Associate at the Centre on Migration Policy and Society (University of Oxford). His research has focused on migrant labour market incorporation, the collection and assessment of migration data, the ageing-migration nexus and migration and integration policies.

Email: cangiano_a@usp.ac.fj 